\title{
The Influence of Lunar Phase on the Germination of Creole Corn in a Controlled Environment
}

\author{
Alessandra Vieira da Silva ${ }^{1}$, Jamerson Fabio Silva Filho ${ }^{2}$, Dalcimar Regina Batista Wangen ${ }^{3}$, \\ Lara Bernardes da Silva Ferreira ${ }^{3}$, Brunna Rithielly Rezende ${ }^{1} \&$ Marcos Fernandes-Sobrinho ${ }^{3}$ \\ ${ }^{1}$ School of Agriculture, São Paulo State University, Botucatu, Brazil \\ ${ }^{2}$ State University of Western Paraná, Paraná, Brazil \\ ${ }^{3}$ Goiano Federal Institute, Urutaí, Brazil \\ Correspondence: Alessandra Vieira da Silva, School of Agriculture, São Paulo State University, Botucatu, Brazil. \\ Tel: 55-64-992-440-620. E-mail: alessandra2014396@gmail.com
}

Received: December 12, 2020

Accepted: January 17, $2021 \quad$ Online Published: February 15, 2021

doi:10.5539/jas.v13n3p61

URL: https://doi.org/10.5539/jas.v13n3p61

\begin{abstract}
Although the influence of lunar phase on plant growth and development has been disregarded by most researchers, there is still little data in the literature regarding the influence of lunar phase within a controlled environment. Objective evaluates the influence of lunar phase on the germination of creole corn and on seedling development in a controlled environment. The experimental design was completely randomized with the following treatments: four lunar phases (full, waxing, waning and new), with four replications totaling 50 seeds per treatment. The treatments started on the first day of the waxing phase and extended to the full phase within the same month, respecting the germination period (nine days) and the length of each moon phase (roughly seven days). The following parameters were evaluated: germination rate, seedling length, fresh and dry weight of shoots and roots. Seedlings germinated during the waning lunar phase were longer and had greater fresh root weight and greater fresh and dry shoot weights than did seedlings germinated during the other phases. However, some limiting factors (long term experiments and in different places in the world) must be considered in future research to determine whether moon phase affects germination. Thus, longer-term, controlled, and modeled studies are needed to analyze external factors, which may influence the germination of cultivar seeds.
\end{abstract}

Keywords: lunar cycle, climate, seed germination

\section{Introduction}

Corn (Zea mays L.) is considered the most significant crop in the world. In recent decades, corn has surpassed wheat and rice, with annual yields greater than one billion tons, and widely diverse applications (Contini, 2019).

Varieties of creole corn are an important resource for breeding (Paterniani et al., 2000). Despite being less productive than commercial cultivars, the creole corn is still widely grown by small farmers because it allows them to reduce costs by producing their own seeds (Meneguetti et al., 2002). In past civilizations, the first calendars were based on lunar phases. These ancient peoples reported several terrestrial phenomena influenced by the moon, such as the growth of plants and human hair. Many of these phenomena have no proven scientific basis (Silveira, 2003; Vasquez et al., 2018). However, different intensities of gravitational forces exerted by the earth and moon do cause tides in maritime waters (Bueno \& Motta, 2005).

According to the fundamentals of biodynamic agriculture, agricultural practices are influenced by the rhythm of the moon, the movements of planets and cosmic forces (Steiner, 2014). According to Rivera (2005) there are times when the moon has a high power of attraction on all liquids on the earth's surface, but at different amplitudes that depend on the physical state, plasticity, and nature of these substances. Due to attraction, the phases of the moon determine the movement of sap within plants.

In general, the effect of lunar influence on plants has been largely disregarded by the scientific community. However, some farmers still use the lunar calendar to determine the timing of field activities (Guia Rural, 1986). For example, Tupis-Guarani indigenous communities in Brazil associate lunar activities with the climate, fauna and flora and follow lunar phases for hunting, planting, and logging (Afonso, 2006). Some studies have attributed aspects of plant development to lunar phases (Menin et al., 2014; Santos et al., 2013; Souza et al., 2003). 
Nevertheless, there is little scientific data related to the influence of lunar phases within a controlled environment. An extensive literature review has already been performed regarding interactions between biological rhythms and lunar phases. This review found that the relation between Moon and Sun phases (synodic rhythm) plays an important role in the establishment of biological rhythms (metabolism, sexuality and behavior) (Endres \& Schad, 1997). Conversely, little is known about the Moon's effects on plants (Goldstein \& Barber, 2000).

Therefore, the aim of this study was to evaluate the influence of lunar phase on seed germination and seedling development of creole corn within a controlled environment.

\section{Method}

\subsection{Field Experiment}

The experiment was carried out at the seed analysis laboratory of the Instituto Federal Goiano, Campus Urutaí, in Urutai, GO, Brazil in September 2018. We used manually processed creole corn seeds or variety from the 2018 harvest in the municipality of Urutaí, Goias, Brazil.

A completely randomized design was used with the following treatments: four lunar phases (full, waxing, waning and new), with four replications of 50 seeds per treatment.

The treatments started on the first day of the waxing phase and extended to the full phase within the same month (1 to 30 September, 2018), respecting the germination period (nine days) and the length of each moon phase (roughly seven days).

The seeds used in the tests were from lots that had been previously homogenized (manually) according to the criteria established by the Brazilian manual on rules for seed analysis (Regras para Análise de Sementes (RAS) (Brasil, 2009). During the experiment, the seeds corresponding to the subsequent lunar phases were stored in kraft paper bags, at room temperature.

\subsection{Variables Analyzed}

The following parameters were evaluated: germination rate, seedling length, and fresh and dry seedling weights.

Germination Test: The test was conducted according to the criteria established by RAS (Brasil, 2009), with 200 seeds per treatment, distributed in four repetitions of fifty units. Two sheets of germination paper (in rolls) (Filter paper) were used as a substrate. These were moistened in a solution of $0.1 \%$ Calcium Nitrate at 2.5 times the weight of the dry paper (Distilled water with twice the weight of paper was used). The test took place in a germination chamber at a constant $25^{\circ} \mathrm{C}$ (constant relative humidity at $25^{\circ}$ ). The first germination count was performed at five days and the final count at nine days (RAS rules).

Seedling Length: Two hundred seeds per treatment, divided in four repetitions of 50 seeds, were also used in this test. The seeds were arranged in a horizontal line in the upper third of two sheets of germination paper (Filter paper). Moisture, germination time and temperature were the same as those used in the germination test (RAS rules, constant relative humidity at $25^{\circ}$ ). A graduated ruler was used to measure the roots and shoots of normal seedlings at nine days after the start of each lunar phase (waxing, full, waning, and new). Mean shoot and root lengths (cm) were calculated from these parameters.

Fresh and Dry Seedling Weights: Weights were determined from normal seedling in the seedling length test. The 50 seedlings from each repetition were placed in a labeled paper bag and weighed (roots and shoots were placed in separate bags), excluding bag weight (tare). The fresh shoot weight (FSW), fresh root weight (FRW), and (average of 50 seedlings) were expressed in grams (g). The same bags (and their contents) were dried in a forced air oven for 48 hours at $60{ }^{\circ} \mathrm{C}$ and weighed on a precision scale. The results were expressed in grams for the means of the dry shoot weights (DSW) and dry root weights (DRW) of each repetition.

\subsection{Data Analysis}

The results were evaluated by multivariate analysis of variance (MANOVA), using R software (R Core Team, 2019), and canonical discriminant analysis, using CANDISC software (Friendly \& Fox, 2017). The treatment values were compared statistically using ellipses (95\% confidence) in biplots.

\subsection{Lunar Cycle}

Gravitational force exerted by the earth, moon and sun on a particle ( $p$ ) located on the earth's surface.

To provide a better understanding of the moon's phases and the approximations used in the model, an illustration of the moon's orbit around the earth follows. Figure 1 illustrates the sun's rays and their effects on the appearance of the moon as it orbits around the earth. Here the moon orbits in a clockwise motion as it would appear from an observer in space above the South Pole. An observer above the North Pole would obviously see the orbit as 
counter-clockwise (lecture). Only the positions of the new (gray circle, between the earth and the sun)-and full moon (white circumference, to the left of the Earth) were considered.

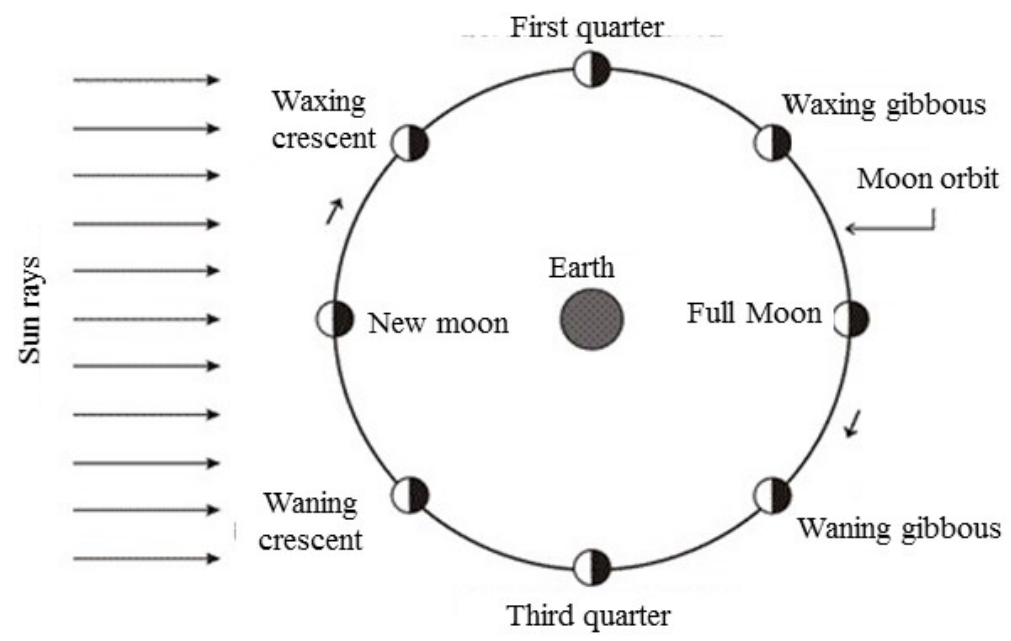

Figure 1. Illustration of the successive phases of the moon. The orbit of the moon is represented in a clockwise direction, as it would appear from space and above the earth's South Pole

Source: Varella and Oliveira (2009).

A particle was selected (for example, an element with mass $m_{p}$ from a seedling) (Figure 2). In the present model, the earth was assumed to be spherical with a uniformly distributed mass $\mathrm{M}_{\mathrm{T}}$ and radius $\mathrm{R}_{\mathrm{T}}$. Rotational effects were disregarded in order to treat the planet as an inertial reference. This approximation was made since the contributions of inertia in the following calculations would be approximately the same during the new and full phases of the moon.

(1) Earth-Moon-Sun system during the new Moon: force diagram
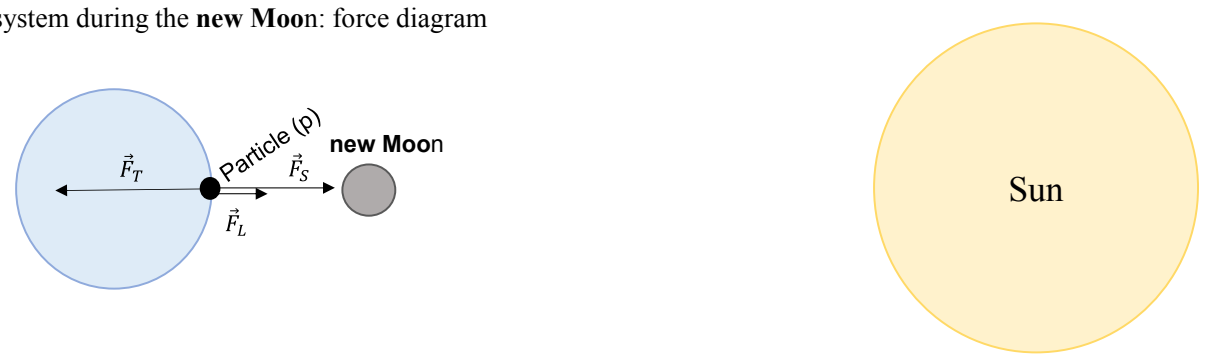

(2) Earth-Moon-Sun system during the full moon: force diagram

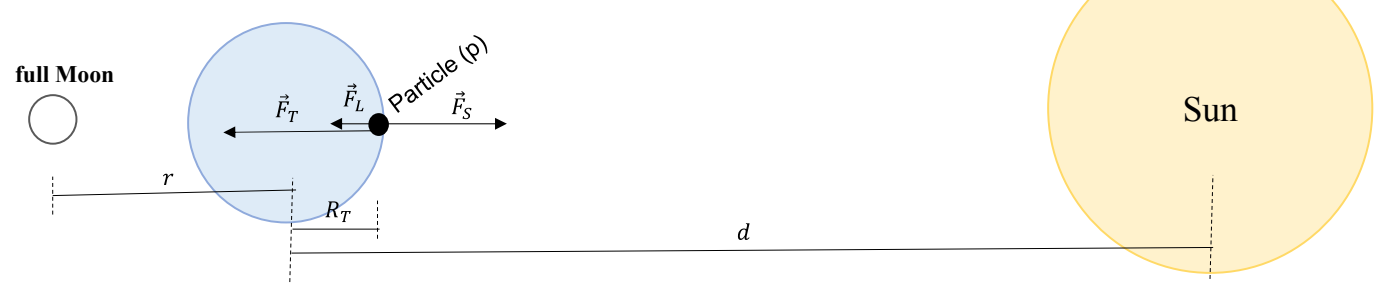

Figure 2. Illustration (not proportional) of the earth moon sun system during the new and full moon phases, respectively: representations of the forces that the earth, the moon and the sun exert on a particle $(p)$ located on the earth's surface

Source: Created by the authors from a lecture by Fernandes-Sobrinho (2016). 
Therefore, given the universal gravitational constant $G$, the force that the earth exerts on a particle, according to Newton's Law of Gravitation, would be (Feynman, 2008; Tipler \& Mosca, 2009):

$$
F_{T}=\frac{G M_{T} m_{p}}{R_{T}^{2}}
$$

Similarly, for the moon, of mass $M_{L}$, where, " $r$ " is the distance between the centers of gravity of the earth and the moon, the intensity of the force that the moon exerts on the particle would be:

$$
F_{L}=\frac{G M_{L} m_{p}}{\left(r-R_{T}\right)^{2}}
$$

Given that $r>>R_{T}$, the following approximation was used:

$$
F_{L} \cong \frac{G M_{L} m_{p}}{r^{2}}
$$

For the sun, of mass $M_{S}$, where, " $d$ " is the distance between the centers of gravity of the earth and the Sun, the force that the sun exerts on a particle would be:

$$
F_{S}=\frac{G M_{S} m_{p}}{\left(d-R_{T}\right)^{2}}
$$

Since $d \gg>R_{T}$, the following approximation was used:

$$
F_{S} \cong \frac{G M_{S} m_{p}}{d^{2}}
$$

Although the moon's orbital plane around the earth is different from the earth's orbital plane around the Sun (Buick \& Pugh, 2011), the model and illustrations in this paper consider a situation in which the three bodies (earth, moon and Sun) are aligned.

Given these considerations, the forces that the earth, moon and Sun exert on a particle of mass " $m$ ", located on the earth's surface and, for the sake of simplicity, to the right of the reader in Figure 2, were assigned. In Figure 2, the force resulting from the contributions of the gravitational interactions of the earth, moon and Sun on particle $(p)$ was determined at the new and full lunar phases.

\subsection{New Moon}

During the new moon, the vectors $\vec{F}_{L}$ and $\vec{F}_{S}$ point in the same direction. The resulting gravitational force on a particle is expressed, vectorially, as: $\vec{F}_{R_{N}}=\vec{F}_{T}+\vec{F}_{L}+\vec{F}$, which in turn can be expressed algebraically as: $F_{R_{N}}=F_{T}-\left(F_{L}+F_{S}\right)$ (Fernandes-Sobrinho, 2008).

\subsection{Full Moon}

During the full Moon, the $\vec{F}_{L}$ and $\vec{F}_{T}$ vectors point in the same direction. Therefore, the resulting gravitational force on a particle is expressed, vectorially, as: $\vec{F}_{R_{N}}=\vec{F}_{T}+\vec{F}_{L}+\vec{F}$, which in turn can be expressed algebraically as: $F_{R_{C}}=\left(F_{T}+F_{L}\right)-F_{S}$ (Fernandes-Sobrinho, 2008).

As mentioned, the rotation of the planet can be ignored since the contribution of this force would be practically the same in each moon phase. The calculations were made by substituting $R_{T}, r, d, G$ and masses $M_{T}, M_{S}, M_{L}$ and $m_{p}=$ $1 \mathrm{~g}$, which resulted in: $\frac{F_{R_{c}}}{F_{R_{\mathrm{s}}}} \cong 1,0000069427$.

This means that that the gravitational force on particle $(p)$ is significantly greater (approximately $0.00069427 \%$ ) during the full moon than during the new moon.

Given that the moon takes approximately 27.3 days to orbit the earth (Saraiva et al., 2007), and that each phase lasts roughly seven days, each mass element on the earth's surface is affected for approximately 15 days (from waxing crescent to waning gibous) (Figure 1) by interactions with the earth, moon and sun, which is substantially smaller and directed into the earth, since it passes through the new moon phase (assuming the clockwise direction shown in Figure 1).

Therefore, if germination takes place during the waning phase, the contribution resulting from these gravitational interactions may facilitate development and possibly germination, since the seed and seedling are somewhat less attracted into the earth.

Conversely, if germination took place in the waxing phase, the effect would be the opposite. In this case, the contribution resulting from gravitational interactions would hinder development or even germination, since the seed and seedling would be somewhat more attracted by the planet. 


\section{Results and Discussion}

Significant differences were found among the treatments. Together, the first two canonical variables explained $86 \%$ of the difference among treatments (Figure 3).

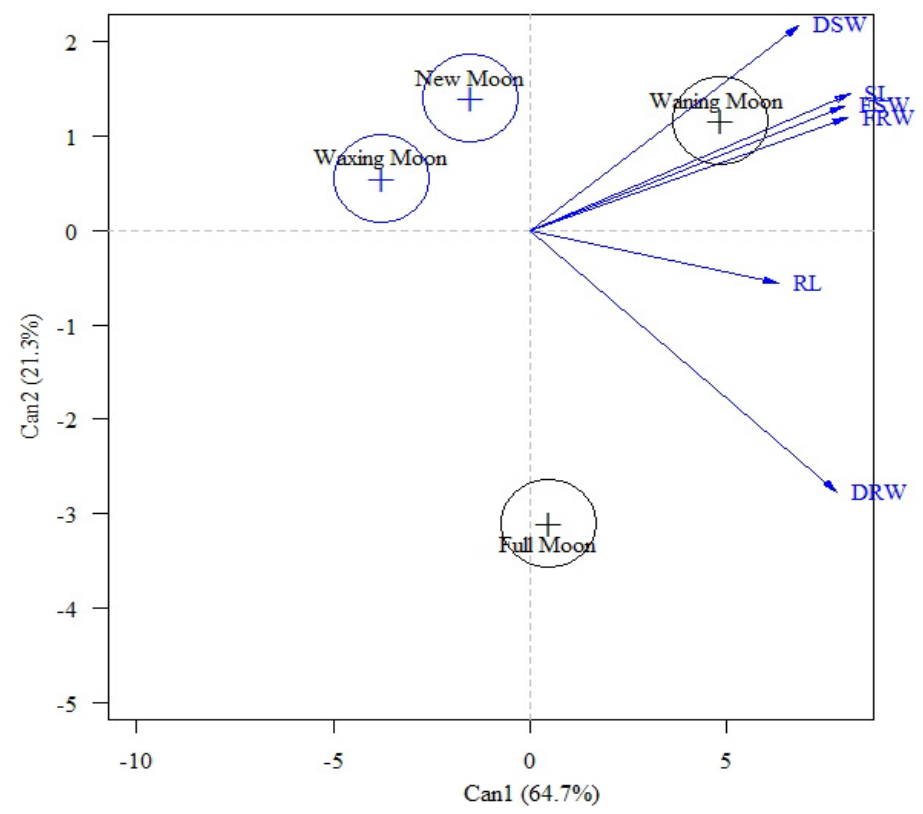

Figure 3. Parameters evaluated in the form of a biplot, according to lunar phase

Note. $\mathrm{SL}=$ shoot length; $\mathrm{RL}=$ root length; FSW = fresh shoot weight; FRW = fresh root weight; DSW = dry shoot weight and DRW = dry root weight.

Source: Produced by authors from research data.

Although, germination was not observably affected, the waning lunar phase was associated with increases in growth (FSW, FRW, DSW and SL).

Rivera (2005) reports that in the waning moon, sap tends to descend and concentrate in stems and branches, which would explain the increase in fresh and dry shoot weights and root lengths in creole corn seedling. A field study of the influence of lunar phases on coriander growth Santos et al. (2013) found greater weight accumulation during the new moon, which agrees with the results from the present study. Conversely, Rivera (2005) found that sap flow concentrated in the roots during the new moon Rivera (2005).

Souza et al. (2003) evaluated carrot production during two lunar cycles and found that shoot and root growth were greater during the waning moon but explained that their results may have been affected by other factors such as temperature.

Research interest regarding the influence of the moon on agriculture has been increasing since the 1970s when organic agriculture began to strengthen in several European countries. Two strategies have arisen from these studies based on lunar calendars: (1) everything that is produced underground such as roots, tubers, rhizomes and edible bulbs, should be planted between the waning gibbous and new moon, and (2) everything that is produced above ground, such as leaves, edible flowers and fruit, should be planted between the waxing crescent and the new full (Rodrigues, 1998). The rational is based on taking advantage of daylight. Thus, less intense luminosity has a positive effect on the soil and can accelerate germination (Rodrigues, 1998).

As can be seen, the few studies that do exist on the influence of lunar phase on plant development are controversial and require further study.

\section{Conclusions}

Given the countless factors that contribute to seed germination and plant growth, the results of the present study are not yet sufficient to affirm whether lunar phases influence the germination rate of creole corn. However, seeds germinated during the waning lunar phase did produce seedlings with longer stems and greater fresh root, fresh stem, and dry stem weights. 
The current study was limited because it did not account for other external aspects that, for example, might have contributed to stronger seedling growth. There is only evidence, according to the calculations performed, of a change in the intensity of the force resulting from the gravitational attraction of the Eearth, the Ssun and the moon on a particle $(p)$, located on the earth's surface. Because this experiment was based on a model, other possible phenomenological factors were neglected, including those related to physical theory. Furthermore, the experiment was not longitudinal, which would allow for the consideration of other possible external influences such as different lighting intensities, day lengths, and humidity levels.

Future studies could consider experiments that are longer in duration, longitudinal, controlled and modeled to analyze other external factors that might affect plants. These studies could also be distributed throughout different regions of the planet and repeated during different seasons to account for different altitudes and longitudes that contribute to variations in the intensity of terrestrial gravitation and encompass other elements that could contribute to a better understanding of the results of this preliminary study.

\section{Acknowledgements}

Federal Institute Goiano-Campus de Urutaí.

\section{References}

Afonso, G. (2006). Myths and seasons in the Tupi Guarani Sky. Scientific American Brasil, 45(4), 46-55.

Brasil, Ministério da Agricultura, Pecuária e Abastecimento. (2009). Regras para análise de sementes (p. 395). Brasília, DF: MAPA/ACS.

Bueno, A. A., \& Motta Jr., J. C. (2005). The moon and small mammals. Revista Ciência Hoje (p. 219).

Buick, T., \& Pugh, P. (2011). How to Photograph the Moon and Planets with Your Digital Camera (2nd ed., p. 366). Springer, London. https://doi.org/10.1007/978-1-4419-5828-0

Contini, E., Mota, M. M., Marra, R., Borghi, E., Miranda, R. A. S., Silva, A. F., ... Mendes, S. M. (2019). Corn-Characterization and Technological Challenges (p. 45). Milho: Caracterização e Desafios Tecnológicos. EMBRAPA, Brazil.

Endres, K. P., \& Schard, W. (1997). Biology des Mondes. Stuttgart: S. Hirzel Publisher.

Fernandes-Sobrinho, M. (2008). Introduction to Classical Mechanic-Physical I (1st ed., p. 116). Brasília-DF: A3 Gráfica e Editora Ltda.

Feynman, R. P. (2008). In R. P. Feynman, R. B. Leighton, \& M. Sands (Eds.), Feynman physics lessons. Porto Alegre: Bookman.

Friendly, M., \& Fox, J. (2017). Candisc: Visualizing Generalized Canonical Discriminant and Canonical Correlation Analysis (R Package Version 0.8-0).

Goldstein, W., \& Barber, B. (2000). Effects of planting dates and lunar positions on carrots cultivation. Biodynamics. Traduzido do inglês por Juliana Klinko.

Guia Rural. (1986). Agricultural Yearbook (pp. 09-10). São Paulo: Editora Abril.

Meneguetti, G. A., Girardi, J. L., \& Reginatto, J. C. (2002). Creole Corn-Viable and Sustainable Technology. Magazine Agroecology and Sustainable Rural Development Revista Agroecologia e Desenvolvimento Rural Sustentável, 3(1), 12-17.

Menin, L. F., Rambo, J. R., Frasson, D. B., Pereira, T. A. X., \& Santi, A. (2014). Influência das fases lunares no desenvolvimento das culturas de rúcula (Eruca sativa Hill) e rabanete (Raphanus sativus L.). Rev. Bras. de Agroecologia, 9, 117-123.

Paterniani, E., Nass, L. L., \& Santos, M. X. (2000). The value of maize genetic resources for Brazil. In C. V. Udry \& W. Duarte (Eds.), Uma história brasileira do milho: $O$ valor dos recursos genéticos (pp. 11-41). Brasília: Paralelo.

$\mathrm{R}$ Core Team. (2019). R: A language and environment for statistical computing. R Foundation for Statistical Computing, Vienna, Austria.

Rivera, J. R. (2005). La luna: El sol nocturno en los trópicos y su influencia en la agricultura (p. 191). Colombia: Manágua.

Rodrigues, L. (1998). Report on the Moon's Influence on Agriculture (p. 20). Vitória, Brazil. 
Santos, L. H., Garcia, R. S. M., Cerqueira, B. R., Carvalho, R. S., \& Ledo, C. A. S. (2013). Influence of the Lunar Cycle on the Development and Yield of Coriander Coriandrum sativum L. Cadernos de Agroecologia (Vol. 18, No. 2). IVIII Congresso Brasileiro de Agroecologia, Porto Alegre, RS.

Saraiva, M. de F. O., Amador, C. B., Kemper, É., Goulart, P., \& Muller, A. (2007). The phases of the Moon in a cardboard box. Revista Latino-Americana de Educação em Astronomia, 4, 9-26. https://doi.org/10.37156/ RELEA/2007.04.009

Silveira, F. L. da. (2003). Tides, maisn phases of the Moon and babies. Caderno Brasileiro de Ensino de Física, 20(1), 10-29.

Souza, S. L. de, Luiz, J. M. Q., Samanta, D. G., \& Monalisa, A. D. S. (2003). Lettuce and carrot production under two lunar cycles. Associação Brasileira de Horticultura, 2, 1-6.

Steiner, R. (2014). Fundamentas of biodynamic agriculture: New life for the land. Rev. Bras. de Agroecologia, 9(3), 17-123.

Tipler, P. A., \& Mosca, G. (2009). Physics for scientists and engineers: With modern physics (6th ed.). W. H. Freeman and Company, New York and Basingstoke.

Varella, I. G., \& Oliveira, P. D. C. F. de. (2009). Fases da Lua 2010. Circular Astronômica (No. 035).

Vasquez, G. H., Giovanini, C., \& Marsoli, G. F. (2018). Interference of moon phases in the development of rubber tree grafts. Nucleus, 15(2). https://doi.org/10.3738/1982.2278.2951

\section{Copyrights}

Copyright for this article is retained by the author(s), with first publication rights granted to the journal.

This is an open-access article distributed under the terms and conditions of the Creative Commons Attribution license (http://creativecommons.org/licenses/by/4.0/). 